\title{
CONTRIBUIÇÕES DO ESTÁGIO CURRICULAR SUPERVISIONADO PARA A PRÁTICA PEDAGÓGICA DE UM PROFESSOR DE EDUCAÇÃO FÍSICA
}

\author{
Moisés SiPRIANo ResendE \\ Universidade de Brasilia (UnB), Brasilia, Distrito Federal, Brasil \\ Eliene Lacerda Pereira \\ Instituto Federal de Educação, Ciência e Tecnologia de Goiás (IFG), Goiânia, \\ Goiás, Brasil
}

\begin{abstract}
Resumo: Esta pesquisa teve por objetivo identificar as contribuições do Estágio Curricular Supervisionado (ECS) para a prática pedagógica de um professor de Educação Física que atua em uma escola campo de estágio na Rede Municipal de Educação de Goiânia, Goiás. Para isso, foi realizada uma entrevista semiestruturada e os dados foram analisados por meio da técnica de análise de conteúdo. Dessa forma, foi possível verificar que o ECS oportuniza ao professor: um espaço para a troca de experiência; a aprendizagem de novos conhecimentos e seu crescimento profissional. Além disso, o estágio auxilia o desenvolvimento do trabalho pedagógico na escola. Sugere-se a realização de novas pesquisas que ampliem o conhecimento da relação entre estagiário, professores e escola.
\end{abstract}

Palavras-chave: Estágio. Professor. Prática Pedagógica. Educação Física.

INTRODUÇÃO

O Estágio Curricular Supervisionado (ECS) é singular na formação de professores, pois permite aos futuros docentes o conhecimento da realidade e da dinâmica escolares. O ECS oferece um espaço propício para os estagiários articularem teoria e prática, elaborarem e desenvolverem planos de intervenção, analisarem a prática pedagógica, trocarem experiências, estabelecerem relações com os educandos etc. No entanto, para que o ECS ocorra, é necessária uma interação profícua entre escola e universidade (ALMEIDA; MOREIRA, 2012).

No âmbito da formação de professores de Educação Física, o ECS tem como objetivo promover o desenvolvimento do futuro professor, tanto profissionalmente como pessoalmente, a fim de que ele possa ser capaz de lidar com as demandas e a realidade da profissão após sua graduação (MOLETTA et al., 2013). 
Algumas pesquisas já analisaram as contribuições do ECS para a formação de professores de Educação Física, seja na ótica dos estagiários (MOLETTA et al., 2013; ALMEIDA; MOREIRA, 2012), seja na perspectiva dos professores das universidades responsáveis pela supervisão dos estudantes (SOUZA; BONELA; DE PAULA, 2007) ou na visão dos professores das escolas (KRUG et al., 2016).

Entretanto, há poucas pesquisas que analisaram as contribuições do ECS à formação e à prática pedagógica do professor colaborador, isto é, aquele professor que atua na escola campo de estágio. Benites et al. (2012), por exemplo, buscaram identificar como o professor de Educação Física e colaborador se vê durante o processo de estágio. Os autores constataram que os professores de Educação Física das escolas aprendem também durante 0 estágio, na medida em que passam a conhecer novas práticas desenvolvidas pelos estagiários. Apesar disso, os autores não procuraram conhecer com profundidade estas aprendizagens, o que indica uma lacuna no que se refere às influências e contribuições do ECS à escola e aos professores que nela atuam.

Como afirmam Krug e Conceição (2008, p.01):

A discussão não pode perder o foco e permanecer em uma espécie de monólogo formativo, mostrando justamente que não só o estagiário recebe a "luz" das contribuições. Mas é uma troca de experiência e saberes que remetem aqueles que estão no contexto educacional a se desenvolverem profissionalmente.

Dessa forma, o estágio pode ser compreendido como um espaço de formação recíproca que envolve, desde seu início, uma mudança na estrutura da escola e no trabalho de seus atores. Como afirmam Krug e Conceição (2008), no processo de estágio há contribuições de ambos os atores envolvidos, o que suscita novas possibilidades de interpretação e intervenção da/na realidade educativa.

Peterle e Conceição (2012), ao investigarem a opinião de professores de Educação Física que atuam em escolas campo de estágio a respeito das contribuições dos estagiários para seu desenvolvimento profissional, identificaram vários aspectos favoráveis, tais como: aquisição de novas possibilidades pedagógicas; reflexão sobre a própria prática; busca de novos conhecimentos; contato com teorias e metodologias mais recentes etc.

É preciso superar, nas pesquisas científicas, a pouca visibilidade do trabalho realizado pelo professor da escola campo de estágio, especialmente pelas limitações colocadas pela própria legislação educacional ao não estabelecer o perfil profissional e tampouco a função desse professor no âmbito do ECS (BENITES et al., 2012).

Assim, emergiu a pergunta: quais seriam as contribuições do ECS à prática pedagógica dos professores de Educação Física das escolas? Esta pesquisa teve como objetivo, então, identificar as contribuições do ECS para a prática pedagógica de um professor de Educação Física que atua em uma escola campo de estágio na Rede Municipal de Educação (RME) de Goiânia.

Este artigo é fruto de uma pesquisa desenvolvida a partir da experiência obtida na disciplina de ECS I da Faculdade de Educação Física e Dança da Universidade Federal de Goiás (FEFD/UFG), no ano de 2011. Durante o estágio, realizado em uma escola pública 
da Rede Municipal de Educação (RME) de Goiânia, houve uma série de debates e discussões entre professores da escola campo, professores supervisores e estagiários acerca das propostas de ensino, das metodologias e dos instrumentos de avaliação em Educação Física mais adequados para as turmas. Nesse ínterim, observamos que o estágio constituiu um rico espaço de aprendizagem, inovação e construção pedagógica no ambiente escolar, superando uma prática docente individual e restritiva.

Dessa maneira, intentamos refletir de forma mais sistemática sobre as contribuições do estágio à escola e à prática pedagógica dos professores de Educação Física. Apresenta-se, a seguir, a metodologia utilizada na pesquisa e em seguida os resultados e análises obtidos a partir da entrevista realizada com um dos professores de Educação Física da escola campo de estágio.

\section{Metodologia}

A pesquisa realizada é de caráter qualitativo, do tipo descritivo, caracterizandose como um estudo de caso. Triviños (1987, p. 133) define o estudo de caso como "uma categoria de pesquisa cujo objeto é uma unidade que se analisa aprofundadamente". Assim, pretendeu-se descrever e analisar com profundidade as contribuições do Estágio Curricular Supervisionado (ECS) para a prática pedagógica da Educação Física, de acordo com a visão de um professor que leciona em escolas públicas da Rede Municipal de Ensino de Goiânia.

Para a coleta dos dados foi realizada uma entrevista semiestruturada, contendo questões previamente estabelecidas que foram apresentadas ao entrevistado a fim de compreender suas percepções a respeito do tema tratado. Para Triviños (1987, p. 146), a entrevista semiestruturada

parte de certos questionamentos básicos, apoiados em teorias e hipóteses, que interessam à pesquisa, e que, em seguida, oferecem amplo campo de interrogativas, fruto de novas hipóteses que vão surgindo à medida que se recebem as respostas do informante. Desta maneira, o informante, seguindo espontaneamente a linha de seu pensamento e de suas experiências dentro do foco principal colocado pelo investigador, começa a participar na elaboração do conteúdo da pesquisa.

A entrevista contemplou questões que buscavam identificar o perfil profissional do professor; possíveis contribuições do estágio para a aprendizagem das crianças, para a escola, para a formação dos futuros professores e para sua prática pedagógica; sugestões para melhorias do estágio; características da relação entre escola e universidade, entre outras. Realizada em fevereiro de 2013, ela foi gravada e posteriormente transcrita para leitura, tratamento e análise.

Os dados foram analisados seguindo a técnica de análise de conteúdo. Assim, foi feita a leitura flutuante da entrevista (corpus documental da pesquisa), buscando o conhecimento do material e a identificação das possíveis categorias de análise. Em seguida, foi realizada a categorização, que consiste na identificação e no agrupamento das unidades de sentido em conjuntos mais amplos, definidos por termos, palavras ou 
expressões capazes de abarcar o sentido das mensagens manifestadas ali presentes (AMADO, 2013).

As categorias construídas no decorrer da leitura e análise da entrevista retratam diferentes contribuições do Estágio Curricular Supervisionado (ECS) para a prática pedagógica da Educação Física segundo a visão do professor da escola campo, dentre elas trocar experiências de ensino, aprender novos conhecimentos e auxiliar no desenvolvimento do trabalho pedagógico. Os dados do trabalho de análise são apresentados e discutidos a seguir.

\section{CONTRIBUIÇÕES DO ECS PARA A PRÁTICA PEDAGÓGICA DO PROFESSOR DE EDUCAÇÃO FÍ́SICA DA ESCOLA CAMPO}

O professor entrevistado possui Licenciatura em Educação Física e Especialização em Educação Física Escolar, Saúde e Atividade física. Atualmente ele trabalha em duas escolas públicas da Rede Municipal de Educação (RME) de Goiânia, nos Ciclos I e II, perfazendo uma carga horária de 60 horas semanais. No momento da entrevista, o professor trabalhava há cinco anos em uma das escolas, e há quatro anos recebia estagiários do curso de Educação Física naquela instituição.

É importante destacar que os Ciclos de Formação de Desenvolvimento Humano (CFDH) são uma forma de organização do ensino, criada no início dos anos 2000, com o intuito de superar o sistema educacional seriado. Os CFDH procuram

proporcionar uma maior organização do tempo e do espaço escolares, considerando e respeitando o tempo e o ritmo de cada aluno, superando assim as grandes dificuldades encontradas nos primeiros anos da vida escolar (PEREIRA, 2010, p. 48).

Na RME de Goiânia, os Ciclos de Formação de Desenvolvimento Humano foram adotados no ano de 1998 e são divididos em Ciclo I (que abrange crianças de 6 a 8 anos), Ciclo II (pré-adolescentes, de 9 a 11 anos) e Ciclo III (adolescentes de 12 a 14 anos) (GOIÂNIA, 2016).

A seguir, as principais contribuições do ECS para a prática pedagógica do professor de Educação Física são apresentadas.

\section{TROCAR EXPERIÊNCIAS DE ENSINO}

Um dos temas destacados pelo professor de Educação Física durante a entrevista foi a troca de experiências de ensino entre os professores da escola campo e os estagiários durante o período de ECS. Exemplos dessas aprendizagens podem ser observados no excerto abaixo.

Como estes estagiários a gente recebe eles todos os anos, então a gente tem muita oportunidade de trocar ideias, a gente tem muita oportunidade de falar um pouco das vivências que a gente tem dentro da escola, da mesma forma aquilo que os estagiários recebem 
como formação dentro da universidade, a gente vai debatendo possibilidades, a gente vai debatendo de certa forma uma prática pedagógica como que pode ser feito dentro da escola. Então acho que existe assim muito uma relação de troca, de experiência (PROFESSOR DE EDUCAÇÃO FÍSICA).

Como é possível observar, o professor relata que o estágio é um momento importante para o intercâmbio de experiências entre os docentes e os estagiários. Os professores da escola possuem conhecimentos acumulados sobre a realidade escolar, enquanto os estagiários apresentam conhecimentos adquiridos na universidade. Esses diferentes conhecimentos são articulados visando à construção de novas e diferentes práticas pedagógicas adequadas ao contexto escolar.

A possibilidade de troca de experiências durante o estágio também é destacada pelas pesquisas de Krug et al. (2016) e Benites et al. (2012). Benites et al. (2012, p. 14), por exemplo, considera que o professor da escola campo de estágio exerce um papel fundamental para a formação dos estagiários ao relatar suas experiências anteriores adquiridas na escola.

\begin{abstract}
O professor da escola de educação básica que recebe estagiários em condição oficial de estágio curricular supervisionado dá aos futuros professores elementos da sua experiência, possibilita que os mesmos descubram os macetes da profissão e oferece condições e espaço para os licenciandos colocarem em prática seus conhecimentos didático-pedagógicos.
\end{abstract}

Desse modo, o estágio se configura como um rico espaço de ampliação de conhecimento e de troca de experiências entre professores da escola e estagiários, culminando na construção de novas e diferentes práticas e possibilidades pedagógicas. Esse aspecto é de fundamental relevância na medida em que as possibilidades de socialização profissional e de troca de conhecimentos são, tradicionalmente, pouco existentes (SACRISTÁN, 2000). Como afirmam Peterle e Conceição (2012), ao trabalhar em conjunto com seus pares o professor se sente mais motivado pedagogicamente a modificar sua prática.

Além da possibilidade de compartilhar experiências, o professor entrevistado destaca como contribuição do ECS a aprendizagem de novos conhecimentos. Esse item será descrito e aprofundado a seguir.

\title{
APRENDER NOVOS CONHECIMENTOS
}

Associada à troca de experiências, a aprendizagem de novos conhecimentos também foi destacada pelo professor como um contributo do ECS à sua prática profissional. O professor relata que, quando recepciona e acompanha os estagiários nas escolas, adquire conhecimentos que enriquecem sua formação docente.

Tem muitos estagiários que têm diferentes práticas, diferentes vivências, diferentes aprendizagens dentro destes conteúdos que a Educação Física trata e, às vezes, isso ajuda a levar isso para dentro da escola de uma forma que às vezes nós que estamos lá há muito 
tempo, às vezes não temos uma forma de ver. Então eu acredito que é uma parceria onde o estágio sim traz contribuições em relação aos conteúdos, em relação às práticas pedagógicas... (PROFESSOR DE EDUCAÇÃO FÍSICA).

Muitos estagiários levam coisas legais para dentro da escola, propostas metodológicas que, às vezes, na época da formação que eu tive não possibilitou que eu visse daquela forma. Então, quando eles trazem estas questões que são novas, estas formas metodológicas desta prática pedagógica com certeza a gente está ali aprendendo, a gente também está se formando, e a gente de certa forma está ali também contribuindo com eles, na melhor forma deles passarem aquilo para os alunos também (PROFESSOR DE EDUCAÇÃO FÍSICA).

O professor ressalta a diversidade de experiências anteriores dos estagiários com os conteúdos da Educação Física, algo que resulta na construção de práticas pedagógicas diferentes e inovadoras em relação àquelas que ele está habituado. Outra questão apresentada pelo professor é o desenvolvimento de propostas metodológicas pelos estagiários; em certos casos essas propostas se mostraram diferentes daquelas por ele utilizadas, o que demonstra um conhecimento que ele não obteve durante sua formação profissional.

A possibilidade de construção de novas práticas pedagógicas no âmbito da Educação Física escolar foi citada pelo professor ao relatar algumas experiências realizadas por estagiários no ensino do atletismo e do futebol.

Da mesma forma também que eu vejo como positivo o fato de muitos estagiários também, o próprio estágio, levar alguns próprios materiais confeccionados pelos alunos, uma possibilidade diferente de trabalho dentro de alguns conteúdos. Tem um exemplo próprio do atletismo quando a gente trabalhou, que alguns estagiários confeccionaram os discos para trabalhar arremesso de disco, os próprios dardos... (PROFESSOR DE EDUCAÇÃO FÍSICA).

Uma dupla de estagiários que levou, como a escola não tinha quadra, eles levaram uma cal e fizeram as marcações de um campo ali no espaço de terra que tinha. Foi um trabalho deles de futebol, que eles passaram as marcações do campo para os alunos (PROFESSOR DE EDUCAÇÃO FÍSICA).

Observa-se que os estagiários utilizaram metodologias diferentes daquelas que são habitualmente empregadas pelo professor, tanto com a produção de materiais alternativos para a vivência das modalidades do atletismo quanto com a organização de espaços adaptados (dispondo de poucos recursos) para a prática do futebol.

A inovação e a adaptação dos conteúdos à realidade das escolas é uma das poucas alternativas possíveis, sobretudo quando as escolas públicas brasileiras, em sua maioria, lidam com a falta de materiais e recursos para a prática de diferentes conteúdos da Educação Física escolar, como os esportes, as lutas, a ginástica etc. 
RESENDE, M. S.; PEREIRA, E. L.

Segundo o professor, iniciativas como esta, além de serem inovadoras, permitem às crianças um aprendizado diversificado dos conteúdos, possibilitando não apenas a sua vivência durante as aulas, mas, também, a criação de condições necessárias para sua realização no contexto extraescolar, ou seja, em seu cotidiano.

Nessa perspectiva, o ECS representou um momento de formação para o próprio professor, pois permitiu o contato com novas teorias, perspectivas e metodologias de ensino recentemente produzidas na universidade. Resultado semelhante também foi encontrado por Benites et al.(2012, p. 21), segundo os autores dois dos cinco professores pesquisados relataram uma visão de: "estágio enquanto troca de experiências entre eles e os estagiários, a oportunidade de estarem próximos da universidade, criando um universo de aprendizagem".

Peterle e Conceição $(2012, \mathrm{~s} / \mathrm{p})$ também identificaram resultados semelhantes ao investigarem a opinião de 11 professores de Educação Física de escolas campo de estágio sobre as possíveis contribuições do estagiário para o aperfeiçoamento de sua prática pedagógica e desenvolvimento profissional. Os autores descrevem que

grande parte dos professores considera que a contribuição do estagiário está na relação da aquisição de novas possibilidades pedagógicas, ou seja, para "ficar por dentro" de novas ideias, novos métodos de ensino, novas tendências, novos esportes. Aproveitam as ideias para melhor ministrar suas aulas, ou simplesmente experimentar novas metodologias juntamente com os alunos.

Essa possibilidade de aquisição de novos conhecimentos para enriquecer a prática pedagógica pode ser de fundamental importância já que o professor, envolvido com as demandas da escola e com a alta carga horária de trabalho, muitas vezes não possui tempo e disponibilidade para buscar cursos de formação continuada.

Em relação a esse aspecto, o professor relata durante a entrevista que a falta de tempo decorrente da grande quantidade de trabalho existente na escola o impede de dar maior atenção aos estagiários, o que limita suas possibilidades de diálogo, compartilhamento e troca de experiências.

Olha, eu acho que como a gente está lá na escola, a gente está numa realidade diferente, é muito... Às vezes a gente não tem um momento para respirar, para se reciclar, um momento para... Eu vejo que o estágio é sempre bem-vindo, mas às vezes é muito corrido. [...] $\mathrm{A}$ gente, às vezes, mesmo um pouco corrido, cede um pouco o horário do recreio para um diálogo, para alguma coisa nesse sentido (PROFESSOR DE EDUCAÇÃO FÍSICA).

Dessa forma, caberia à escola pensar em alternativas para organizar o tempo disponível, buscando acolher os estagiários e viabilizar o planejamento coletivo e a interação entre professores e estagiários. Considerações semelhantes a esta foram identificadas na pesquisa de Krug et al. (2016) e Almeida e Moreira (2012). Krug et al. (2016), por exemplo, aplicaram questionários a 22 professores da educação básica e verificaram que uma das principais sugestões apresentadas pelos participantes foi a destinação de mais tempo para interação entre os estagiários e o professor da escola. Nesse contexto, os professores manifestaram a necessidade de discutir mais o 
planejamento e de trocar experiências com os estagiários, entre outras mudanças. Outra sugestão apresentada pelos professores na pesquisa de Krug et al. (2016) foi a ampliação do tempo de estágio, oportunizando mais momentos de aprendizagem aos estagiários.

\section{AUXILIAR NO DESENVOLVIMENTO DO TRABALHO PEDAGÓGICO DA ESCOLA}

Além da contribuição à prática pedagógica, o professor cita que os estagiários também auxiliam no trabalho pedagógico desenvolvido na escola. Eles fazem sugestões e participam do desenvolvimento de projetos educativos relacionados à Educação Física durante eventos escolares, tais como a festa junina e o dia da criança.

Exemplos dessa participação dos estagiários em projetos da escola podem ser verificados no relato transcrito a seguir.

Seja em uma festa junina, de ajudar ali na formação e construção de uma quadrilha, que eles mesmos tenham esta experiência de vivenciar junto com os alunos, no dia das crianças que eles se proponham a trazer oficinas para as crianças... [...] Alguns alunos foram com aulas de dança, com propostas de oficinas de dança, com propostas de oficinas de jogos e brincadeiras, enfim, de várias oficinas que de certa forma também contribuíram na organização do trabalho pedagógico durante estas festividades (PROFESSOR DE EDUCAÇÃO FÍSICA).

Imersos na perspectiva e na possibilidade de aprenderem a ser professores, os estagiários buscaram e construíram situações de ensino e aprendizagem. Isso os permitiu estreitar os laços com as crianças e com a comunidade escolar, ao mesmo tempo em que ofereceu um grande auxílio aos professores na organização e dinamização da escola durante os eventos.

Em relação a isso, o professor destaca também outra experiência de ensino protagonizada pelo estágio na escola.

A professora de estágio [...] levou os instrumentos de capoeira para que a gente fizesse uma prática corporal, já que a escola não tinha o atabaque, não tinha o berimbau, a gente dispunha na verdade nas aulas só do $C D$ de música da capoeira, por conta que faltava os materiais. Então ela levou aquilo para escola de certa forma onde nas aulas onde a gente trabalhou a capoeira, mas... No dia da consciência negra, por exemplo, foi possível, com o material que ela levou a gente construir uma roda de capoeira, onde os alunos de certa forma expuseram aquilo que eles haviam aprendido nas aulas de Educação Física, que foi muito bacana também. Inclusive sendo solicitado até na época uma matéria de um jornal que a gente fizesse uma matéria de jornal e enviássemos para eles com as fotos que foram feitas para mostrar este trabalho da consciência negra na escola, através destes atos, deste conteúdo, no caso que foi a capoeira (PROFESSOR DE EDUCAÇÃO FÍSICA). 
Nota-se que o estágio teve um papel fundamental na condução do ensino de capoeira nas aulas de Educação Física, por meio dele os materiais e instrumentos musicais necessários à realização dessa prática corporal, que não existiam na escola, foram disponibilizados. Com esses recursos foi possível realizar inclusive uma roda de capoeira durante a comemoração do dia da consciência negra na escola.

O desenvolvimento de projetos educativos pelos estagiários nas escolas também foi indicado como sugestão pelos professores em pesquisa realizada por Krug et al. (2016). Os professores pesquisados ressaltam a necessidade de desenvolver projetos educativos com as crianças, tais como jogos, resgate de brincadeiras antigas, gincanas etc., o que poderia ser protagonizado pelos estagiários de Educação Física e pela própria universidade, não apenas no momento do ECS, mas no decorrer do ano letivo.

Os exemplos citados acima indicam que o estágio não apenas contribui com a organização e desenvolvimento de projetos educativos, mas que o componente curricular Educação Física possui papel singular na realização de eventos e festas comemorativas na escola. Assim, o estágio pode se tornar um meio de colaboração com o professor de Educação Física na organização desses eventos, embora seja preciso reconhecer que a função do professor se dá principalmente na condução das aulas e do projeto de ensino estabelecido por ele e pela instituição'.

Além disso, a modificação do recreio foi mais uma contribuição dos estagiários ao trabalho pedagógico, segundo relata o professor. Ele descreve que havia forte segregação entre as crianças ao usarem os espaços da instituição (quadra, pátio, entre outros) durante o recreio. Após as sugestões dos estagiários, a administração da escola modificou a estrutura do recreio, passando a oferecer também jogos e atividades direcionadas.

\begin{abstract}
Os meninos maiores, às vezes, excluíam os meninos menores e acabavam tomando o espaço, por exemplo, da quadra... E aí hoje na escola, depois de certo tempo, a gente mudou [...]. O recreio agora é divido e na hora do recreio também hoje já tem mais algumas atividades, vamos dizer assim, que é direcionada pela própria escola, pela própria coordenação, no caso a coordenação de turno que tem, deixa disponível certo momento ali, uma caixa com cordas para quem quiser brincar, uma caixa com brinquedos tipo boliche para quem quiser brincar, uma caixa com uns bambolês para quem quiser... Então, as crianças elas mesmas vão pegando e vai tendo um pouco este controle meio que livre, elas pegam aquilo que elas têm mais interesse e vão brincar (PROFESSOR DE EDUCAÇÃO FÍSICA).
\end{abstract}

Observa-se, assim, que a sugestão dos estagiários passou a ser considerada pela escola, o que produziu mudanças na organização e no uso dos espaços e materiais da instituição durante o recreio. Com a divisão do recreio entre maiores e menores, e a disponibilização de brinquedos e materiais pedagógicos as crianças poderão ter mais liberdade, prazer e ludicidade durante o intervalo.

Nessa perspectiva, um olhar externo ao da escola e dos professores pode auxiliar na identificação de problemas e na construção de soluções que busquem a melhoria do trabalho pedagógico e da formação oferecida pela instituição. Sobre esse aspecto, a pesquisa realizada por Peterle e Conceição (2012) identificou que os professores da escola campo consideram que o estágio os ajudou a repensar sua prática. Ao mesmo tempo 
também os incentivou a buscar novos conhecimentos e a ter contato com pesquisas e discussões recentes realizadas na área da Educação Física.

Dessa forma, podemos concordar com Ventorim (2003, $\mathrm{s} / \mathrm{p}$ ) quando ele afirma que "o estágio não só usufrui e se utiliza do espaço da escola, mas, sobretudo, forma-a e se forma com ela". Por fim, o professor defende a presença do estágio na escola e sugere ainda uma maior inserção desta prática no cotidiano escolar. Para ele, é necessário o estreitamento do diálogo e do vínculo entre escola e universidade a fim de avançar "na construção de uma educação, de uma educação física que contribua para a formação dos alunos dentro do chão da escola" (PROFESSOR DE EDUCAÇÃO FÍSICA).

\section{CONSIDERAÇÕES FINAIS}

Embora seja um período de formação dos futuros professores, o estágio também promove melhorias na prática pedagógica dos professores das escolas campo. O professor de Educação Física entrevistado relata alguns benefícios do estágio, como permitir a troca de experiências, promover a aprendizagem de novos conhecimentos e auxiliar no desenvolvimento do trabalho pedagógico na escola.

$O$ docente troca suas experiências profissionais adquiridas no cotidiano da escola com o estagiário, que Ihe transmite parte do conhecimento obtido na formação inicial. $O$ tempo disponível para compartilhar experiências, no entanto, é pouco, em virtude da dinâmica e da grande quantidade de demandas existentes na escola.

No contexto do estágio, o professor relata aprender novos conhecimentos teóricos e metodológicos empregados no ensino dos conteúdos da Educação Física. Durante a intervenção dos estagiários, ele tem contato com novas práticas pedagógicas, muitas vezes inacessíveis durante a sua formação, oportunizadas pela diversidade de experiências trazidas pelos estagiários. Essa possibilidade de enriquecer a prática pedagógica durante o estágio revelou-se importante para o desenvolvimento profissional do professor, considerando a dificuldade de tempo para realizar cursos de formação continuada.

De acordo com o professor, os estagiários também auxiliaram a condução e organização do trabalho pedagógico desenvolvido pela escola, seja na proposição de alternativas de mudança e melhoria da escola, seja na participação de projetos educativos e eventos realizados pela instituição.

Nessa perspectiva, o estreitamento dos vínculos entre professor da escola campo de estágio, professores supervisores das universidades e estagiários possibilita o aprimoramento da prática profissional dos professores, incentiva a adoção de novas práticas pelos estagiários, favorece a organização da escola e oferece novas e diferentes aprendizagens aos educandos.

Assim, esta pesquisa auxiliou na identificação das contribuições do ECS na prática pedagógica e na formação profissional do professor de Educação Física da escola campo de estágio. Embora a pesquisa retrate a realidade de um caso específico, ela poderá incrementar os estudos existentes sobre a relação entre ECS e escola, algo que, como demonstrado, ainda é incipiente.

Além das questões identificadas, poderiam ser exploradas também as contribuições que o ECS oferece à aprendizagem dos educandos; a opinião deles a 
respeito do ensino desenvolvido pelos estagiários, além da observação de possíveis mudanças de atitudes e comportamentos dos educandos durante a sua relação com estagiários etc.

Artigo recebido em: $31 / 10 / 2018$

Aprovado para publicação em: 18/04/2019

\section{CONTRIBUTIONS OF THE SUPERVISED CURRICULAR STAGE FOR THE PEDAGOGICAL PRACTICE OF A TEACHER OF PHYSICAL EDUCATION}

ABSTRACT: The objective of this research was to identify the contributions of the Supervised Curricular Internship (ECS) to the pedagogical practice of a Physical Education teacher who works in a traineeship school in the Municipal Education Network of Goiânia, Goiás. For this, a semistructured interview was conducted and the data were analyzed using the technique of content analysis. It was identified that the ECS gives the teacher a space for the exchange of experience, the learning of new knowledge, and also help in the development of the pedagogical work in the school. It was observed that the internship also constitutes a space of professional development of the teacher. It is suggested to carry out new researches that increase the knowledge of the relation between trainee, teachers and school.

KEYWORDS: Stage. Teacher. Pedagogical Practice. Physical Education.

\section{CONTRIBUCIONES DE LA ETAPA CURRICULAR SUPERVISADA PARA LA PRÁCTICA PEDAGÓGICA DE UN PROFESOR DE EDUCACIÓN FÍSICA}

RESUMEN: Esta investigación tuvo por objetivo identificar las contribuciones de la Etapa Curricular Supervisionado (ECS) para la práctica pedagógica de un profesor de Educación Física que actúa en una escuela de campo de prácticas en la Red Municipal de Educación de Goiânia, Goiás. Para ello, se realizó una entrevista siniestrada y los datos se analizaron mediante la técnica de análisis de contenido. Se identificó que el ECS permite al profesor un espacio para el intercambio de experiencia, el aprendizaje de nuevos conocimientos, además de auxiliar en el desarrollo del trabajo pedagógico en la escuela. Se observó que la etapa se configura también como un espacio de desarrollo profesional del profesor. Se sugiere la realización de nuevas investigaciones que amplíen el conocimiento de la relación entre pasante, profesores y escuela.

PALABRAS CLAVE: Etapa. Maestro. Práctica pedagógica. Educación Física.

NOTA

1) Sacristán (2000) considera que o professor realiza uma série de atividades no contexto escolar, tais como supervisão, orientação, ensino, coordenação, entre outras. No entanto, o que caracteriza e define sua prática profissional são as atividades relacionadas ao ensino, o que inclui o planejamento, a preparação de atividades e materiais, a explicação do conteúdo, a elaboração de provas etc. 


\section{REFERÊNCIAS}

ALMEIDA, F. F. V.; MOREIRA, E. C. Contribuições da disciplina de Estágio Supervisionado de um curso de Licenciatura em Educação Física: a percepção discente. Conexões: revista da Faculdade de Educação Física da UNICAMP, Campinas, v. 10, n. 2, p. 77-102, mai./ago. 2012.

AMADO, J. M. Manual de investigação qualitativa em educação. Coimbra: Imprensa da Universidade de Coimbra, 2013.

BENITES, L. C. et al. Qual o papel do professor colaborador no contexto do estágio curricular supervisionado na Educação Física? Revista Brasileira de Ciência e Movimento, 20 (4): p. 13-25, 2012.

GOIÂNIA, Secretaria Municipal de Educação e Esporte. Proposta Político-Pedagógica para a Educação Fundamental da Infância e da Adolescência. Secretaria Municipal de Educação e Esporte, Superintendência Pedagógica e de Esportes, Diretoria Pedagógica, Gerência da Educação Fundamental da Infância e da Adolescência - Goiânia (GO), 2016. $132 \mathrm{p}$.

KRUG, H. N.; CONCEIÇÃO, V. J. S. Contribuições do Estágio Supervisionado no desenvolvimento profissional de professores de educação Física: novas propostas de conteúdo, novas visões educacionais. In: XII Congresso Ciências do Desporto e Educação Física dos Países de Língua Portuguesa, 2008, Porto Alegre. Anais [...]. Porto Alegre: UFRGS, 2008. v. 1. p. 1-10.

KRUG, H. N. et al. Estágio Curricular Supervisionado em Educação Física: as sugestões de melhoria na visão do professor-colaborador da educação básica. Revista Conteúdo, Capivari, v.11, n.1, jul./dez. 2016.

MOLETTA, A. F. et al. Momentos marcantes do Estágio Curricular Supervisionado na formação de professores de Educação Física. Pensar a Prática, Goiânia, v. 16, n. 3, p. 715730, jul./set. 2013.

PEREIRA, E. L. A Educação Física na organização do trabalho pedagógico em ciclos de aprendizagem na Rede Municipal do Recife. 2010. Dissertação (Mestrado em Educação Física) Universidade de Pernambuco, ESEF/UPE.

PETERLE, G.; CONCEIÇÃO, V. J. S. O estágio supervisionado no desenvolvimento docente: a opinião dos professores de Educação Física. EFDeportes.com, Revista Digital, Buenos Aires, ano 15, no 166, mar. 2012.

SACRISTÁN, J. G. O currículo: uma reflexão sobre a prática. Porto Alegre: Editora Artmed, 2000. 
RESENDE, M. S.; PEREIRA, E. L.

SOUZA, J. C. A.; BONELA, L. A.; DE PAULA, A. H. A importância do Estágio Supervisionado na formação do profissional de Educação Física: uma visão docente e discente.

MOVIMENTUM - Revista Digital de Educação Física, Ipatinga, v.2, n² 2, ago./dez. 2007.

TRIVIÑOS, A. N. S. Introdução à pesquisa em ciências sociais: a pesquisa qualitativa em educação. São Paulo: Atlas, 1987.

VENTORIM, S. A produção do conhecimento sobre prática de ensino e estágio supervisionado em Educação Física na Revista Motrivivência. In: Congresso Brasileiro de Ciências do Esporte, 13, 2003, Caxambu. 25 anos de história: o percurso do CBCE na educação física brasileira. Anais [...]. Florianópolis: Colégio Brasileiro de Ciências do Esporte, 2003.

MoIsÉs SIPRIANO RESENDE: Licenciado em Educação Física pela Universidade Federal de Goiás (UFG). Especialista em Direitos Humanos e em Letramento Informacional pela UFG. Mestrando do Programa de Pós-graduação em Educação Física pela Universidade de Braślia $\left(U_{n B}\right)$. Professor da Rede Municipal de Educação de Goiânia, Goiás.

Orcid: https://orcid.org/0000-0003-2903-4442

E-mail:msxufg@smail.com

Eliene Lacerda Pereira: Mestre em Educação Física pela Universidade de Pernambuco e Especialista em Educação Física Escolar pela Universidade Federal de Goiás. Professora no Instituto Federal de Educação, Ciência e Tecnologia de Goiás. Tem experiência na área de Educação, atuando principalmente nos temas: educação física, prática pedagógica, cultura escolar, metodologia, organização do trabalho pedagógico, currículo e formação de professores.

E-mail: elienemorango@gmail.com

Este periódico utiliza a licença Creative Commons Attribution 3.0, para periódicos de acesso aberto (Open Archives Iniciative - OAI) 